\title{
PEMFC MEA and System Design Considerations
}

\author{
S. Knights ${ }^{\mathrm{a}}$, R. Bashyam, P. He, M. Lauritzen, C. Startek, V. Colbow, T. T. H. Cheng, J. \\ Kolodziej, and S. Wessel \\ a Ballard Power Systems, Inc, 9000 Glenlyon Parkway, Burnaby BC V5J 5J8, Canada
}

\begin{abstract}
Proton exchange membrane fuel cells (PEMFCs) are being developed and sold commercially for multiple near term markets. Ballard Power Systems is focused on the near term markets of backup power, distributed generation, materials handling, and buses. Significant advances have been made in cost and durability of fuel cell products. Improved tolerance to a wide range of system operation and environmental noises will enable increased viability across a broad range of applications. In order to apply the most effective membrane electrode assembly (MEA) design for each market, the system requirements and associated MEA failures must be well understood. The failure modes associated with the electrodes and membrane degradation are discussed with respect to associated system operation and mitigating approaches. A few key system considerations that influence MEA design include expected fuel quality, balance-of-plant materials, time under idle or open circuit operation, and start-up and shut-down conditions.
\end{abstract}

\section{Introduction}

PEM fuel cells are being developed and sold commercially for multiple near term markets. Ballard Power Systems is actively putting fuel cells to work in high-value commercial uses every day, with a focus on the near term markets of:

- Backup power for the wireless telecommunications industry.

- Distributed generation units operating on available low-cost by-product hydrogen, primarily from chemical production or bio-gas.

- Materials handling for battery replacement in forklift trucks in North American high volume distribution centers and factories.

- Buses for government supported zero-emission transit programs.

Significant improvements have been achieved in cost and durability for fuel cell products over recent years. The cost of Ballard products were reduced by an average of $45 \%$ from 2008 to 2010, and are offered with an operating life of between 2,500 h to $30,000 \mathrm{~h}$, depending on market requirements. In addition to reductions in stack cost and increased durability, improved tolerance to a wide range of system operation and environmental noises will enable increased viability across a broad range of applications. In order to apply the most effective membrane electrode assembly (MEA) design for each market, the system requirements and associated MEA failures must be well understood. At the same time, concurrent development for different applications offers the ability to understand how common issues, such as start-up/shut-down degradation, high cell 
voltages at low loads, and internal transfer/crossover development, can fundamentally be best mitigated with the broadest-capability MEA and system designs.

The design of an integrated fuel cell system requires a detailed trade-off analysis of system and MEA interactions. For example, the choice of fuel, whether from hydrogen or a reformer system, and the amount of carbon monoxide (CO) clean-up in the system, has MEA implications, particularly with respect to the anode design. Figure 1 displays a simplified schematic of some key system and MEA design decisions and potential outcomes when operating on reformed fuel. The use of strategies to mitigate electrode degradation on start-up/shut-down, and membrane degradation impacts due to various operating conditions, are important, as outlined in the schematic below. Operation on pure hydrogen, which involves slightly simpler though still complex considerations, is not shown in order to simplify an already complex discussion. This paper will describe some of the MEA design decisions to increase robustness to system conditions and potential non-specified operating conditions or system noise implications, such as cell reversal tolerance and metal ion contamination.

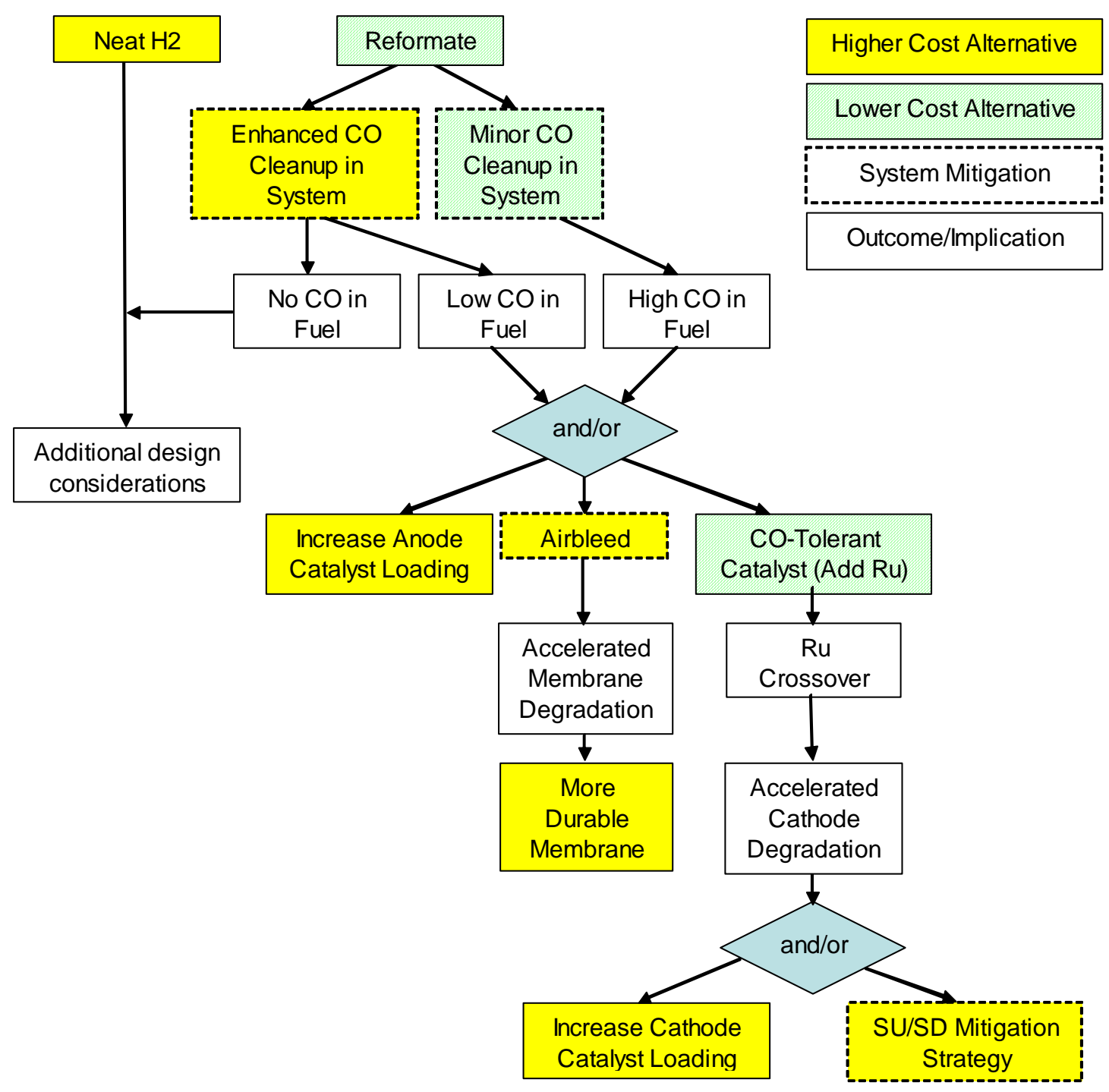

Figure 1. Schematic of system/MEA design considerations for reformate based fuel. 


\section{Discussion}

Key system considerations and associated MEA design parameters for both performance and durability will be discussed in terms of: i) catalyst/electrode related considerations; ii) membrane related considerations; and iii) interactions between both electrode and membrane considerations.

\section{$\underline{\text { Catalyst/Electrode Degradation and MEA/System Considerations }}$}

Reformate Operation: The source of fuel can have a significant impact on cell performance, particularly when operating on reformed fuel which may contain $\mathrm{CO}$, typically at ppm levels. These concentrations are sufficient to poison the $\mathrm{Pt}$ anode catalyst at typical PEMFC operating temperature, and cause a dramatic performance loss in the cells, as shown in Figure 2. The CO poisoning is due to the high adsorption energy and the slow oxidation rate of the adsorbed species $\left(\mathrm{CO}_{\mathrm{ad}}\right)$ at the Pt catalyst sites in the low electrochemical potential range $(<0.3 \mathrm{~V}$ vs. standard hydrogen electrode (SHE)). Consequently, the $\mathrm{CO}_{\mathrm{ad}}$ molecules block the $\mathrm{Pt}$ sites and inhibit the adsorption and oxidation of $\mathrm{H}_{2}$ molecules.

For a given level of $\mathrm{CO}$ in the incoming fuel, the $\mathrm{CO}$ tolerance of the stack can be improved either through a system strategy, such as the use of an air bleed, which involves adding a small percentage of air into the fuel just prior to entry to the anode, or through the use of more $\mathrm{CO}$ tolerant anode catalysts or catalyst layer design.

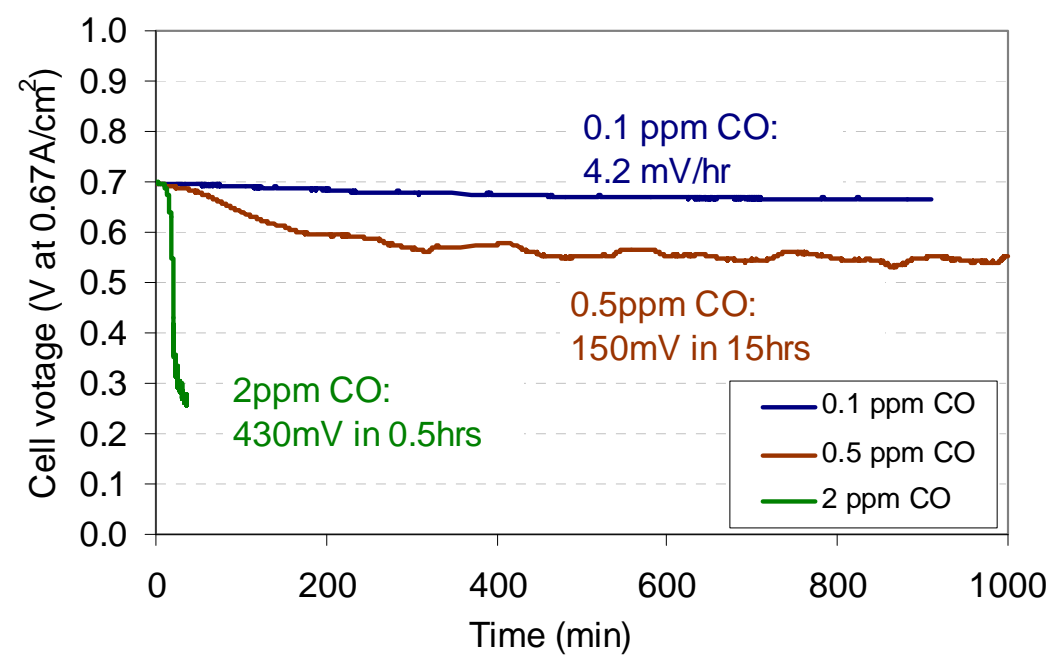

Figure 2. Influence of $\mathrm{CO}$ on fuel cell performance. Hardware: small-scale single cell; Testing conditions: $75^{\circ} \mathrm{C}, 5$ psig, $100 \% \mathrm{RH}$; Fuel: $\mathrm{H}_{2}$ switched to $\mathrm{H}_{2}+\mathrm{CO}$ at the $5^{\text {th }}$ min; Oxidant: air; Anode: $0.1 \mathrm{mg} / \mathrm{cm}^{2} \mathrm{Pt} / \mathrm{C}$.

Impact of Anode Catalyst Loading on CO Tolerance: Platinum-ruthenium catalysts have improved activity for $\mathrm{CO}$ oxidation compared to $\mathrm{Pt}$ and are widely adopted in reformate fueled PEMFC and for direct methanol fuel cells (1). The CO tolerance of the anode is dependent on the anode catalyst loading, as shown in Figure 3a, both with and without airbleed. No significant impact on performance is seen on pure $\mathrm{H}_{2} /$ air (not shown). The CO tolerance comparison was made at $1 \%$ air bleed for 10 and $50 \mathrm{ppm} \mathrm{CO}$ 
and at 3\% airbleed for $500 \mathrm{ppm} \mathrm{CO}$. Good $\mathrm{CO}$ tolerance was observed for $10 \mathrm{ppm} \mathrm{CO}$ even at $0.04 \mathrm{mg} / \mathrm{cm}^{2}$, but higher $\mathrm{CO}$ levels had an increasing impact at the low loadings.

Low anode catalyst loading had a large negative impact on the $\mathrm{CO}$ tolerance performance without airbleed as is seen from Figure $3 \mathrm{~b}$. At $2 \mathrm{ppm} \mathrm{CO}$, loss of around 75 $\mathrm{mV}$ occurs at $1 \mathrm{~A} / \mathrm{cm}^{2}$ and over $200 \mathrm{mV}$ loss occurs at $10 \mathrm{ppm}$ CO. The largest effect was observed as the catalyst loading was decreased from $0.1 \mathrm{mg} / \mathrm{cm}^{2}$ to $0.04 \mathrm{mg} / \mathrm{cm}^{2} \mathrm{Pt}$ for 10 ppm CO. These results indicate that reducing the anode loading below $0.1 \mathrm{mg} / \mathrm{cm}^{2}$ to reduce MEA cost can have substantial negative performance impacts in the presence of CO.
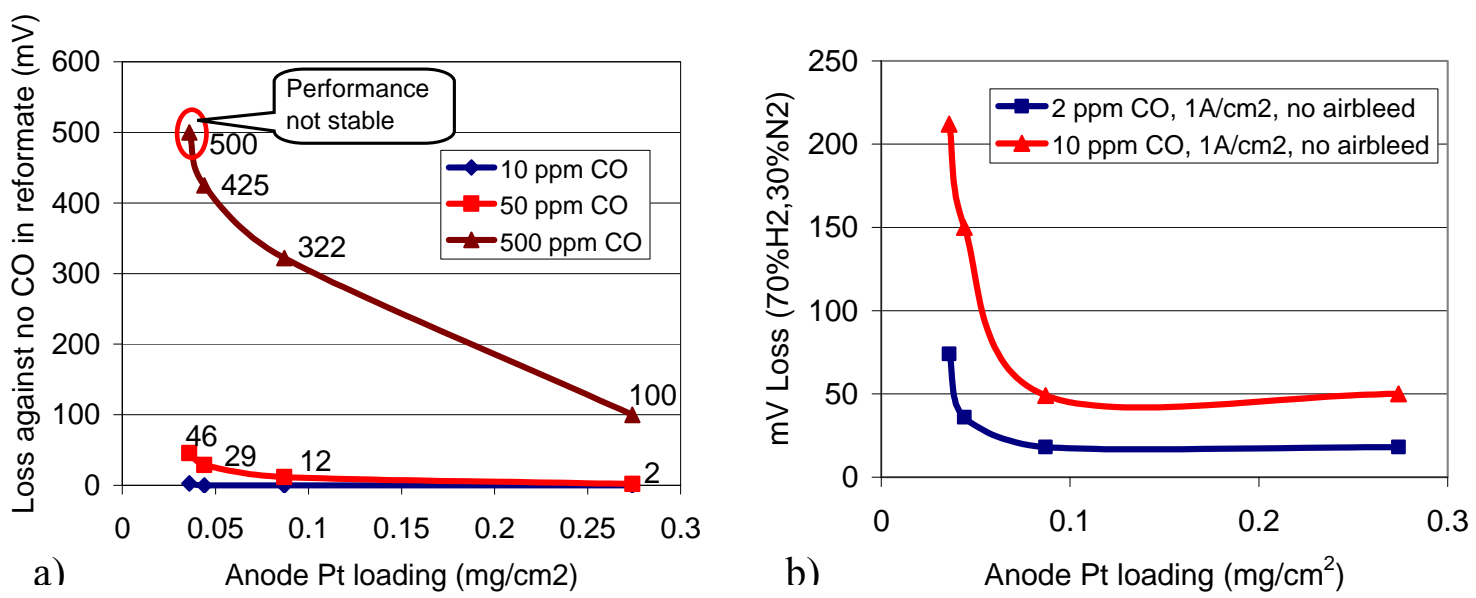

Figure 3. Impact of $\mathrm{CO}$ on performance as a function of anode $\mathrm{PtRu} / \mathrm{C}$ loading. Testing Conditions: $75^{\circ} \mathrm{C}$, 5psig, $100 \% \mathrm{RH}$; Fuel: $70 \% \mathrm{H}_{2}$ and $30 \% \mathrm{~N}_{2}$; Oxidant: air. (a) $1 \%$ air bleed for 10 and 50 ppm CO and 3\% air bleed for 500 ppm CO; (b) no airbleed.

Anode Durability: Durability is a further consideration for anode design. PtRu catalysts are generally not stable and tend to dissolve and degrade and under certain fuel cell operating and non-operating conditions. The $\mathrm{Ru}$ instability is greatly increased when the anode potential rises above the Ru dissolution limit of $\sim 0.45 \mathrm{~V}$ vs SHE, such as during an air-air start (air initially on both cathode and anode prior to drawing a load), shutdown conditions when air may enter the anode, or fuel starvation while drawing a load. The crossover of dissolved $\mathrm{Ru}$ through the membrane and further deposition at the cathode Pt catalyst suppresses the rate of the cathode oxygen reduction reaction (ORR) by blocking Pt sites, and it can also promote a faster oxidation and de-activation of the cathode catalyst $(2,3)$. This can result in a significant durability issue, as shown in Figure 4. 


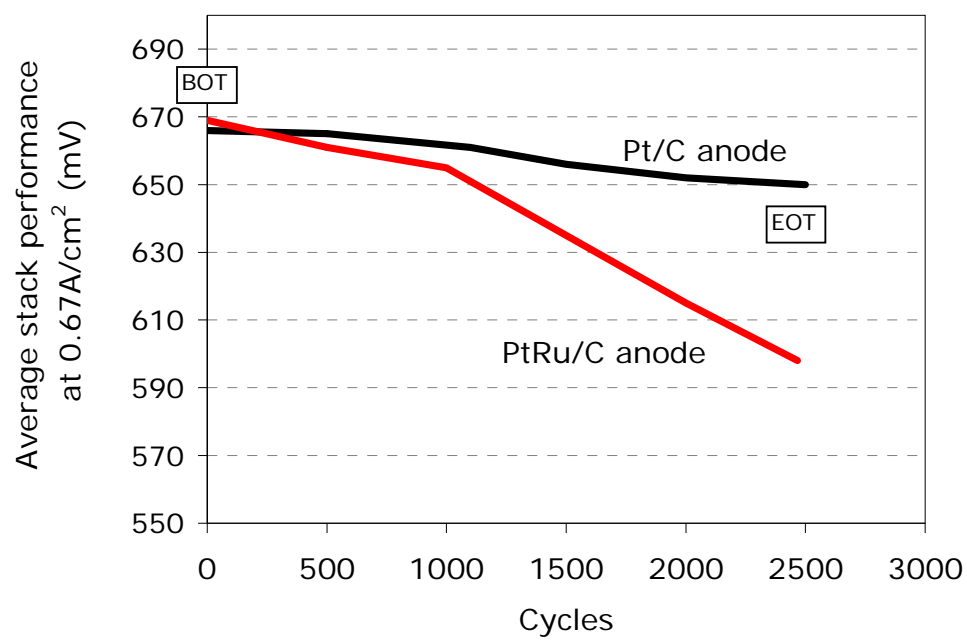

Figure 4. Effect of air/air startup/shutdown on average stack performance. Hardware: 10cell stack; Testing conditions: ambient pressure, $100 / 93 \% \mathrm{RH}$ and $60^{\circ} \mathrm{C}$; Fuel: $70 \% \mathrm{H}_{2}$ and $30 \% \mathrm{~N}_{2}$; Oxidant: air; Anode: $0.1 \mathrm{mg} / \mathrm{cm}^{2}$.

Impact of Cathode Catalyst Loading on Ruthenium Cross-Over Effects: The impact of $\mathrm{Ru}$ crossover on varying levels of low Pt loaded cathodes was investigated in order to understand if the performance loss due to $\mathrm{Ru}$ deposition on the cathode is exacerbated with lower cathode loadings. Figure 5 shows the resulting hydrogen-air polarization performance loss at $0.67 \mathrm{~A} / \mathrm{cm}^{2}$ for MEAs with different Pt loadings on the cathode and $0.1 \mathrm{mg} / \mathrm{cm}^{2}$ on the anode after 2500 anode air-air start-up/shut-down (SU/SD) accelerated stress test (4) cycles. The voltage loss decreased linearly with increasing cathode catalyst loading. Very high voltage losses of $\sim 400 \mathrm{mV}$ and $\sim 275 \mathrm{mV}$ were observed for $0.1 \mathrm{mg} / \mathrm{cm}^{2}$ and $0.25 \mathrm{mg} / \mathrm{cm}^{2}$ cathode loadings. The ex-situ elemental analysis of $\mathrm{Ru}$ on the cathode side of the MEAs after the end of test (EOT) polarization revealed $\mathrm{Ru}$ loading as high as $42 \mu \mathrm{g} / \mathrm{cm}^{2}$. In contrast, the losses observed for non-Ru containing MEAs, even for $0.1 \mathrm{mg} / \mathrm{cm}^{2} \mathrm{Pt}$ cathode loading, are insignificant and independent of catalyst loading.

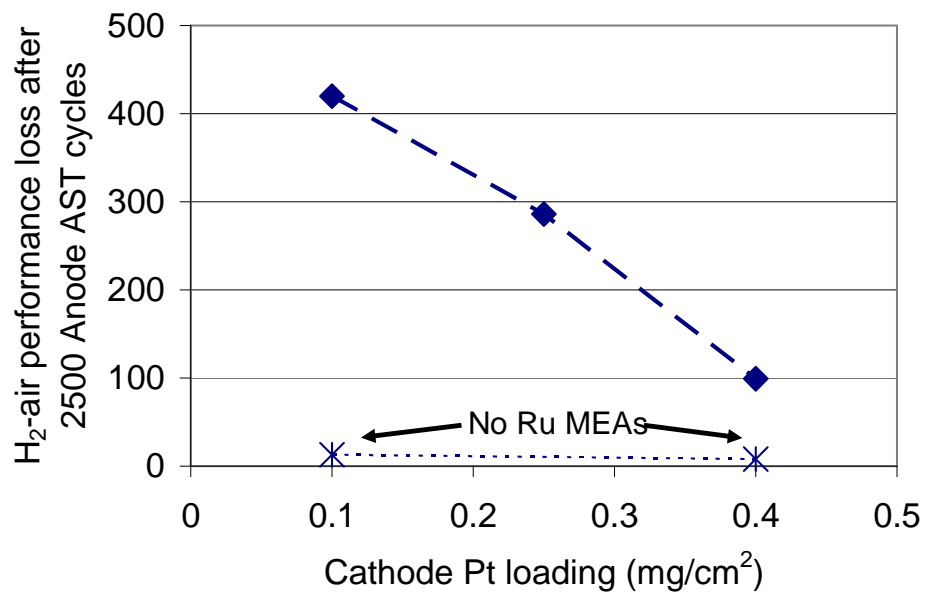

Figure 5. Impact of $\mathrm{Ru}$ crossover on performance after 2500 anode AST cycles - effect of cathode Pt loading. Hardware: small-scale single cell; Testing conditions: $75^{\circ} \mathrm{C}, 5 \mathrm{psig}$, $100 \% \mathrm{RH}, \mathrm{H}_{2} /$ air; Anode: $0.1 \mathrm{mg} / \mathrm{cm}^{2} \mathrm{PtRu} / \mathrm{C}$. 
It is evident from the above results that $\mathrm{Ru}$ crossover is a significant issue in reformate operated PEMFC application and the most effective approach needs to be considered, such as: MEA design strategies for mitigation of $\mathrm{Ru}$ crossover; alternative ruthenium free $\mathrm{CO}$ tolerant anode catalyst without any trade off in $\mathrm{CO}$ tolerance performance; or removal of $\mathrm{CO}$ in the system prior to reaching the fuel cell to eliminate the requirement for $\mathrm{Ru}$ on the anode.

Start-Up/Shut-Down Cathode Degradation: During SU/SD the simultaneous presence of hydrogen and oxygen on the anode, which occurs due to the exit and entry of air on the anode, results in localized high cathode potentials and subsequent $\mathrm{Pt}$ dissolution and agglomeration and carbon corrosion on the cathode. To better understand and predict the impacts of high potential excursion on Pt loss and MEA performance, accelerated stress tests (ASTs) with various upper potential limits (UPLs) were employed to identify the degradation mechanisms and to quantify the degradation rates for $\mathrm{Pt}$ catalysts supported on corrosion-resistant carbon. Figure 6 shows the performance and effective catalyst surface area (ECSA) losses as a function of cycle number. The performance losses were found to be minimal for UPLs $\leq 1.2 \mathrm{~V}$, but dramatically increased at UPLs $>1.2 \mathrm{~V}$. The abrupt change is due to the shift in dominating degradation mechanism: Pt agglomeration at UPLs $\leq 1.2 \mathrm{~V}$ as indicated by an increase in Pt particle size, and carbon corrosion at UPLs $>1.2 \mathrm{~V}$, as indicated by a change in cathode catalyst layer thickness (see Figure 7). In addition, the effect of a short (2 s) highpotential $(1.3 \mathrm{~V})$ spike, a cycling profile similar to that of $\mathrm{SD} / \mathrm{SU}$ of some fuel cell stack systems, was also demonstrated in Figure 6. The shorter dwell time at the high UPL resulted in significantly lower degradation and was found to be essentially identical to results obtained from ASTs with sustained time at a lower UPL (1.2 V).
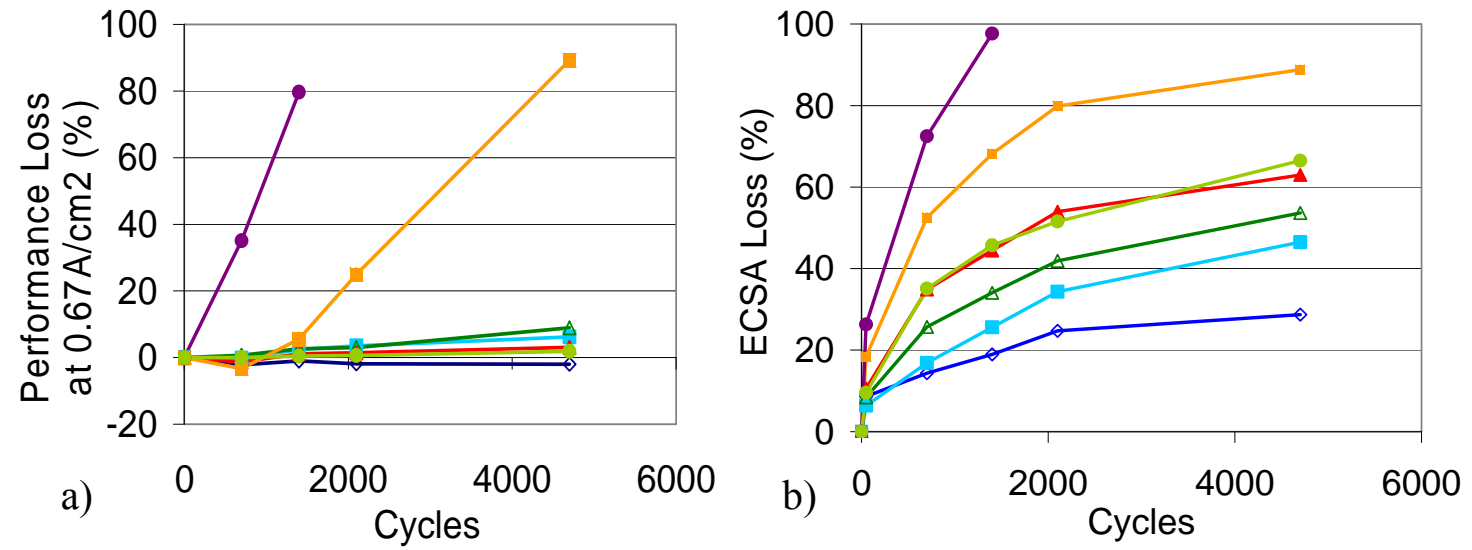

$$
\begin{array}{ll}
\rightarrow 0.9 \mathrm{~V} \text { UPL Pt Cathode } & -1.0 \mathrm{~V} \text { UPL Pt Cathode } \\
\triangle-1.1 \mathrm{~V} \text { UPL Pt Cathode } & -1.2 \mathrm{~V} \text { UPL Pt Cathode } \\
\rightarrow-1.3 \mathrm{~V} \text { UPL Pt Cathode } & \rightarrow-1.4 \mathrm{~V} \text { UPL Pt Cathode } \\
\rightarrow-1.0 \mathrm{~V} \text { UPL, 1.3V spike Pt Cathode } &
\end{array}
$$

Figure 6. Effect of UPL on (a) air performance loss and (b) ECSA loss. Cathode Loading: $0.4 \mathrm{mg} \mathrm{Pt} / \mathrm{cm}^{2}$. 

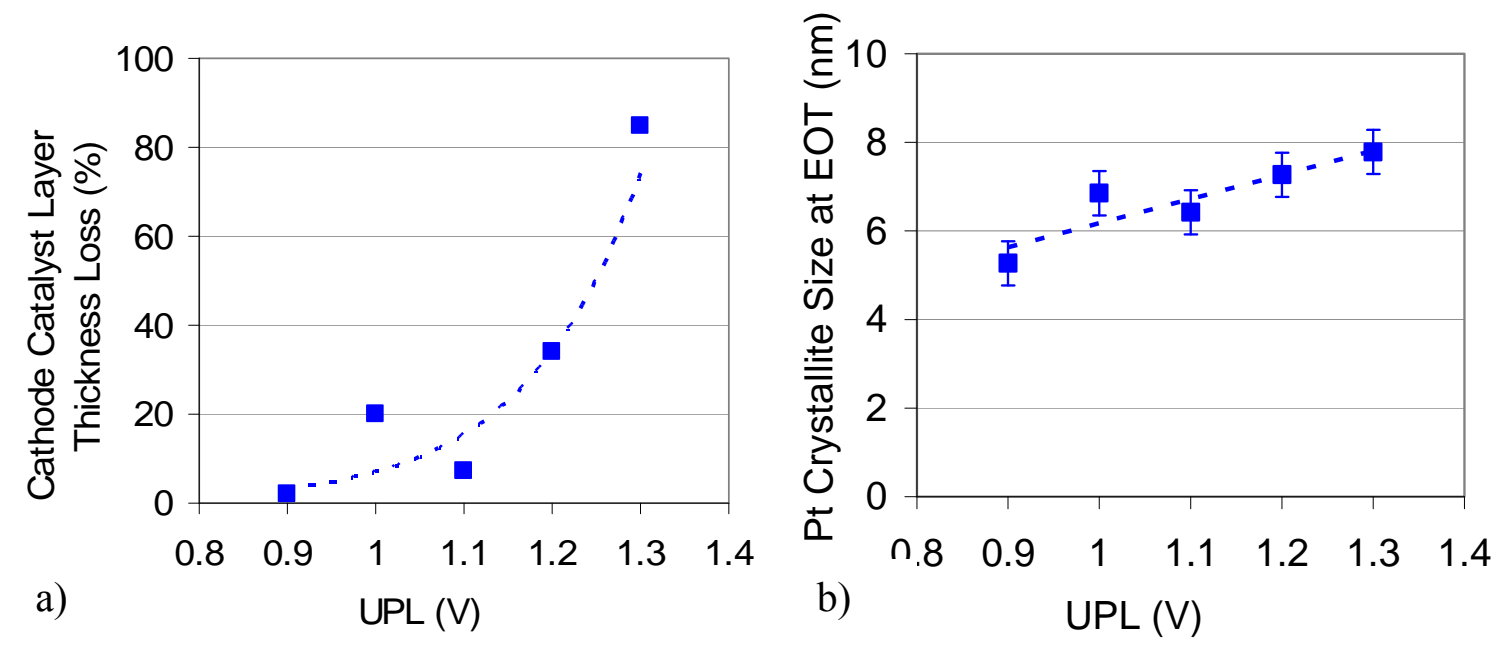

Figure 7. Effect of UPL on (a) EOT Pt crystallite size, and (b) Cathode catalyst layer thickness losses.

Start-Up/Shut-Down Mitigation Strategies: Various materials and system strategies can be employed to reduce SU/SD degradation. The use of more durable MEA materials and designs can provide significant benefit, such as more durable carbon catalyst supports. An example of the benefit of using more corrosion resistant support material is shown in Figure 8a, where the more corrosion resistant support sustained less voltage degradation over the duration of the increased potential AST at 1.4 V.

In terms of system mitigation, keeping cell voltage low on start-up and ensuring rapid exchange of gases will reduce the severity and duration of the corrosion mechanism (5). In Figure $8 \mathrm{~b}$, it can be observed that the rate of cathode corrosion can be reduced by almost 5 times if a direct current load is applied to the stack to reduce the cell voltage to $\leq 0.4 \mathrm{~V}$ during anode air $/ \mathrm{H}_{2}$ gas transients, as the resultant peak cathode potential is reduced.

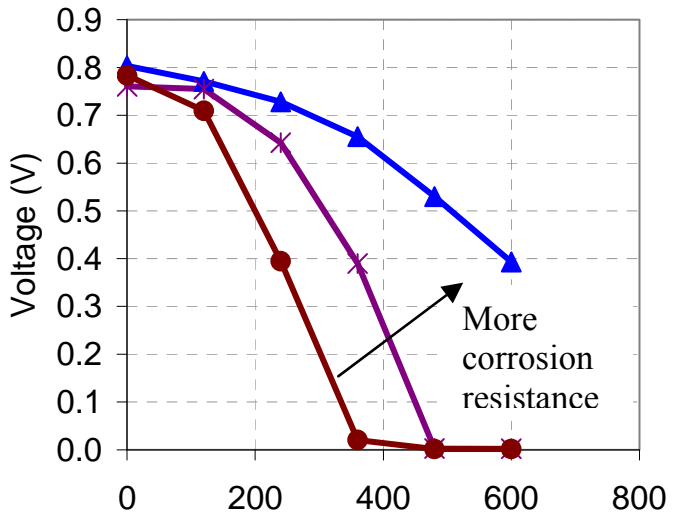

a)

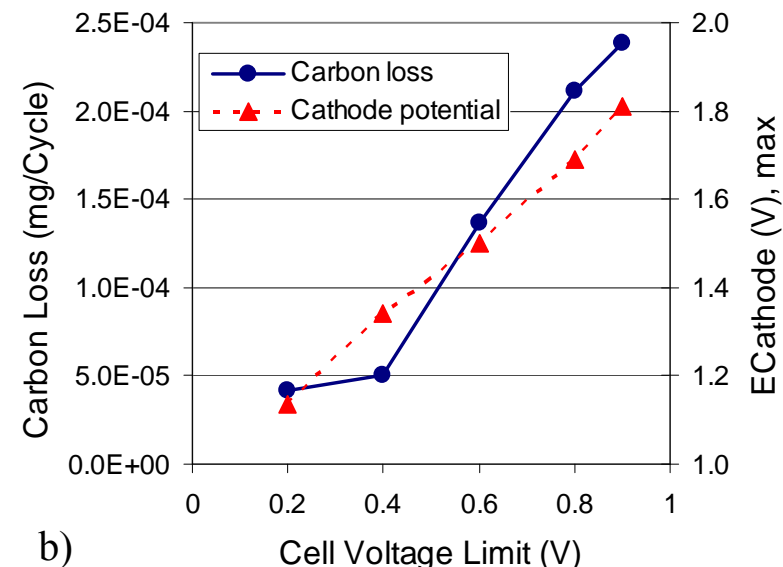

Figure 8. Two strategies for start-up/shut-down corrosion mitigation. (a) Varying corrosion resistance of cathode catalyst supports. Single cell data for $1.4 \mathrm{~V}$ hold, periodic performance checks. (b) Cathode potentials and carbon corrosion rates during startup conditions under anode gas transients from air to $\mathrm{H}_{2}$. 
Applying a combination of both material and system strategies will provide the best overall reduction in degradation as observed in Figure 9. This represents a series of tests, as follows: 1) baseline test with no mitigation; 2) rapid removal of air on the anode on start-up to reduce the duration of the corrosion event; 3) rapid gas exchange is combined with voltage control on start-up; and 4) both system mitigations are combined with a more corrosion resistant cathode. The lifetime benefit of this approach needs to be balanced against the increased cost of the system and MEA strategies.

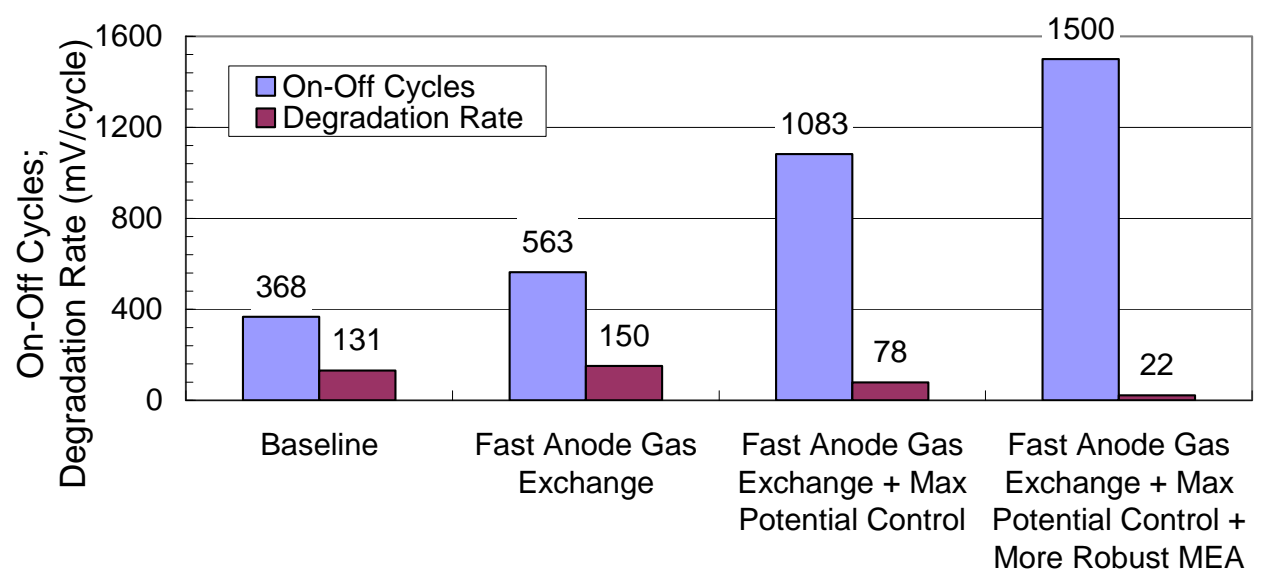

Figure 9: Impact of start-up corrosion mitigation strategies in a stack test, showing increased number of on-off cycles and reduced degradation rates with increased system mitigation.

Fuel Starvation and Cell Reversal: Fuel starvation on the anode may also occur during operation, and the use of cell reversal tolerant anode catalyst should be considered in terms of required fault tolerance and system design to ensure adequate reactant delivery. Fuel starvation on the anode occurs when there is insufficient hydrogen in any cell or group of cells in a stack and the anode is thus unable to produce sufficient protons to maintain the current being supplied and forced through those cells by the rest of the cells in the stack $(6,7)$. This can happen due to system control failures, loss of anode recirculation in systems with hydrogen pumps, fuel pressure-drop variations, by undersupply of reactants during fast up-transients in motive systems, or flowfield blockages such as due to water or ice formation. During those times, the affected cells can undergo cell voltage reversal caused by an increase in anode potential until either or both the carbon oxidation reaction (COR) and oxygen evolution reaction (OER) occurs at a sufficient rate to provide the required protons and sustain the stack current. If the COR reaction occurs, the anode catalyst can be significantly degraded and the cell suffers performance loss.

While it can be argued that fuel starvation and the resulting cell reversals should not occur in properly designed and operated systems, the reality of PEM fuel cell design is that some level of tolerance to cell reversal is highly beneficial and desirable to improve robustness to off-spec operating conditions. As an example, if start-up from frozen capability is required (even in motive systems that have heaters for freeze protection), cell reversal tolerance can be critical to the stack surviving start-up where ice blockages on the anode may be difficult to completely avoid and should be considered a necessary 
rather than desired aspect of cell design. Additionally, there is a financial benefit for stacks being able to absorb a system failure that can cause fuel starvation as the fuel cell stack is typically the most expensive element of the power train.

Figure 10 shows the significance of adding a cell reversal tolerant catalyst (RTC) in the fuel cell stack. In this case, a 10-cell stack simulated a group of cells suffering fuel starvation in a larger stack, with the larger stack voltage simulated by a power supply. The stack without the RTC had a poor reversal tolerance time of $<30 \mathrm{~min}$, at which point the stack voltage had quickly escalated to $-20 \mathrm{~V}$ indicating an average cell voltage of $<$ $2 \mathrm{~V}$. Subsequent performance, when returned to normal operation, dropped by $90 \mathrm{mV}$ at $1 \mathrm{~A} / \mathrm{cm}^{2}$. However, the stack with RTC was able to sustain an extended period of cell reversal of $>5 \mathrm{~h}$ and maintained the stack voltage to less than $-10 \mathrm{~V}$. The stack with RTC lost only $50 \mathrm{mV}$ at $1 \mathrm{~A} / \mathrm{cm}^{2}$ under normal operation, even though the duration of the event was over 10 times in length of the non reversal tolerant design. Examples of cell reversal tolerant anode designs can be found in literature (8).



Figure 10. Cell reversal tolerance for a 10 -cell stack at $0.2 \mathrm{~A} / \mathrm{cm}^{2}$. CRT conditions: Air $/ \mathrm{N}_{2}, 0.2 \mathrm{~A} / \mathrm{cm}^{2}$ reversal current, $30 / 30 \mathrm{psig}, 75^{\circ} \mathrm{C}, 100 / 100 \% \mathrm{RH}$; Polarization conditions: $\mathrm{air} / \mathrm{H}_{2}$ at $1 \mathrm{~A} / \mathrm{cm}^{2}$.

\section{$\underline{\text { Membrane Related Degradation and MEA/System Considerations }}$}

Each fuel cell application has a specific set of membrane degradation related stressors and trade-offs, with much commonality between different applications. For example, the use of fuel cells in motive operation can result in extensive time at low power or open circuit voltage (OCV) conditions, resulting in high cell voltages, which is known to cause increased membrane chemical degradation (9). In transit bus operation, cell voltages $>0.8 \mathrm{~V}$ occur for $>30 \%$ of the duration of the duty cycle. This can be further exacerbated by the use of battery hybridization, for example in buses or materials handling, where heavy use of batteries can increase time at idle, or with no power draw. Another example is for stationary or cogeneration power applications, which often run on reformed fuel and at lower current density to maintain high fuel efficiency, which is critical to the value proposition for these applications. In this case, in addition to the high voltages, the use of an air bleed to mitigate losses due to the presence of $\mathrm{CO}$ can also increase membrane chemical degradation. Finally, for all applications, the presence of 
metal contaminants which may enter the stack from the system can further accelerate the membrane degradation.

Membrane Degradation Under Air-Bleed Conditions: Under the low-potential conditions at the anode $(0-0.2 \mathrm{~V}, \mathrm{SHE})$, purely Pt-based catalysts exhibit a high degree of surface-coverage by adsorbed and dissociated hydrogen atoms. Oxygen, from the air bleed, or in lesser amounts from oxygen cross-over from the cathode, reacts at the anode under these conditions to produce hydrogen peroxide, according to:

$$
\begin{aligned}
& \text { Pt-H }+\mathrm{O}_{2} \rightarrow \cdot \mathrm{OOH} \\
& \cdot \mathrm{OOH}+\mathrm{Pt}-\mathrm{H} \rightarrow \mathrm{H}_{2} \mathrm{O}_{2}
\end{aligned}
$$

Due to the high surface-coverage of hydrogen on the Pt surface at low potentials, local concentrations of $\mathrm{H}_{2} \mathrm{O}_{2}$ increase as there is a sparsity of bare Pt sites available for $\mathrm{H}_{2} \mathrm{O}_{2}$ reduction via:

$$
\begin{gathered}
2 \mathrm{Pt}+\mathrm{H}_{2} \mathrm{O}_{2} \leftrightarrow 2 \mathrm{PtOH} \\
2 \mathrm{PtOH}+2 \mathrm{H}^{+}+2 \mathrm{e}^{-} \leftrightarrow 2 \mathrm{Pt}+2 \mathrm{H}_{2} \mathrm{O}
\end{gathered}
$$

Fluoride evolution from perfluorosulfonic acid (PFSA) membranes then increases due to chemical attack of the polymer by reactive hydroxy radicals that are produced by reaction of $\mathrm{H}_{2} \mathrm{O}_{2}$ with impurities like $\mathrm{Fe}^{2+}$ and $\mathrm{Cu}^{2+}$ :

$$
\mathrm{H}_{2} \mathrm{O}_{2}+\mathrm{M}^{2+} \rightarrow \mathrm{M}^{3+}+\cdot \mathrm{OH}+\mathrm{OH}^{-}
$$

Figure 11 shows the effect of an increasing amount of air bleed in the fuel to increase the membrane fluoride washout rate, a measure of membrane chemical degradation.

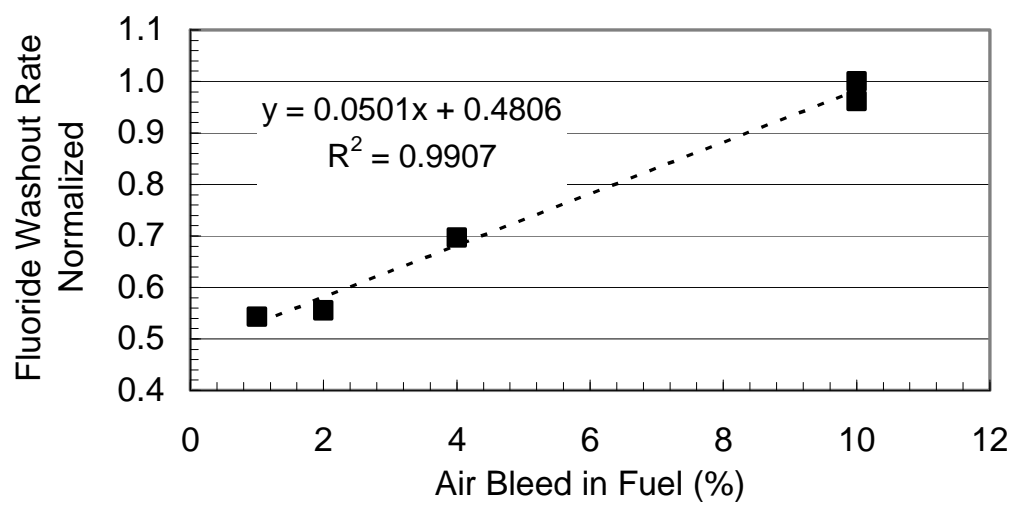

Figure 11. Effect of air bleed on normalized membrane fluoride washout rate at $65^{\circ} \mathrm{C}$, idle conditions.

System strategies to reduce membrane degradation include, for example: operating the stack air-starved in idle or stand-by to drop cell voltages, reducing or eliminating the use of an air bleed, using Ru catalyst on the anode, and ensuring a clean system without metal contamination such as iron, generally the most problematic for membrane degradation. 
Unlike pure-Pt catalysts, PtRu catalysts may exhibit weaker adsorption of hydrogen atoms on the surface, leaving more active sites available for the reduction of $\mathrm{H}_{2} \mathrm{O}_{2}$, according to reactions [3] and [4], and lower membrane degradation rates (see Figure 12).

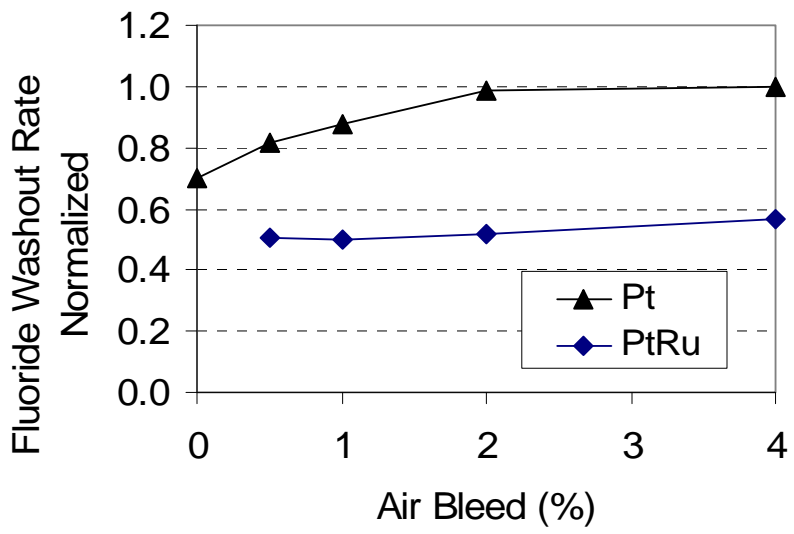

Figure 12. Fluoride loss at open-circuit as a function of air-bleed level for $\mathrm{Pt} / \mathrm{C}$ and $\mathrm{PtRu} / \mathrm{C}$ anode catalysts.

Impact of iron contamination on membrane degradation: The design of the plate and the injection of iron can play a role in localized membrane thinning. In the example shown in Figure 13, the membrane thinning is occurring approximately $4 \mathrm{~mm}$ from the edge of the MEA, which is co-incident with the first channel on the plate. The iron was measured at up to $250 \mathrm{ppm}$ in the membrane after $5000 \mathrm{~h}$.

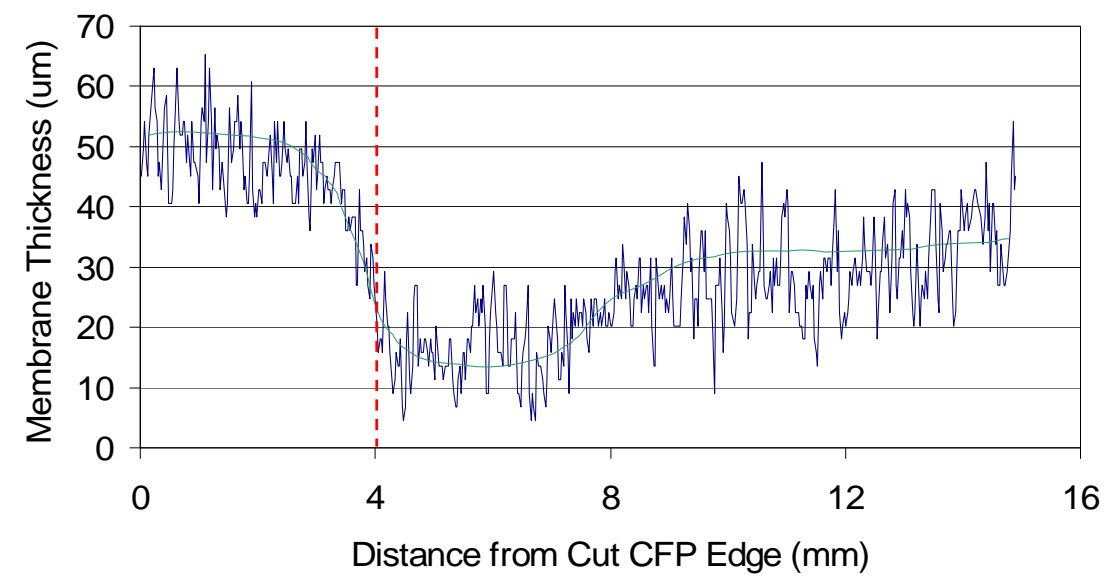

Figure 13. Membrane thickness plot showing thinning spot coincident with inlet flow channel.

A second set of stacks with the same MEA design was operated in an iron reduced system. The levels of iron were confirmed to be below $50 \mathrm{ppm}$ and there was no membrane thinning observed after $4000 \mathrm{~h}$ on test (See Figure 14). 


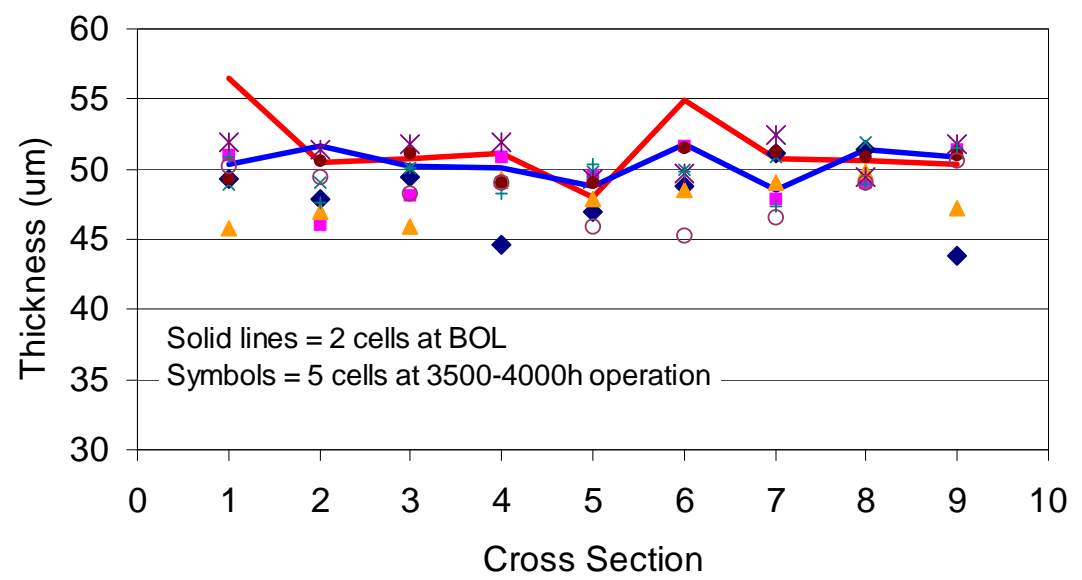

Figure 14. Membrane thickness measured in cross-section at 9 spots in the MEA in a reduced iron system after $4000 \mathrm{~h}$, no thin spots were observed.

Membrane Degradation Mitigation: The membrane ionomer's inherent chemical stability has been improved by reducing the concentration of reactive hydrogen and carboxylic acid end groups through post-fluorination steps (10), while the mechanical stability has been increased through the addition of porous reinforcement layers (11) (e.g. expanded polytetrafluoroethylene (PTFE)), cationic crosslinking agents (12), and with the use of micro-phase separated bi-continuous blend concepts. Some stabilization concepts may impact the performance characteristics of the membrane and mitigations may be required to compensate for a reduced effective ionomer concentration (porous supports) or a lower effective ionomer equivalent weight (cationic additives). Polymer membrane chemical stability has been further improved with the addition of various transition metal cations $(12,13)$ like $\mathrm{Mn}^{2+}$ and $\mathrm{Ce}^{3+}$, as well as their oxides $(14,15)\left(\mathrm{MnO}_{2}\right.$, $\mathrm{CeO}_{2}$ ), and heteropoly acids $(16,17)$ of which some have proven to be both effective hydrogen peroxide decomposition catalysts and radical scavengers.

Figure 15 indicates the large improvements in lifetime and chemical stability that can be achieved with individual and combined chemical and mechanical mitigation strategies. As mentioned, some of these mitigation strategies can also negatively impact performance, and nanocomposites with inherent proton conductivity like $\mathrm{MnO}_{2} / \mathrm{SiO}_{2}$ $\mathrm{SO}_{3} \mathrm{H}$ have been reported (18) to reduce their impact on the ionomer proton conductivity. 


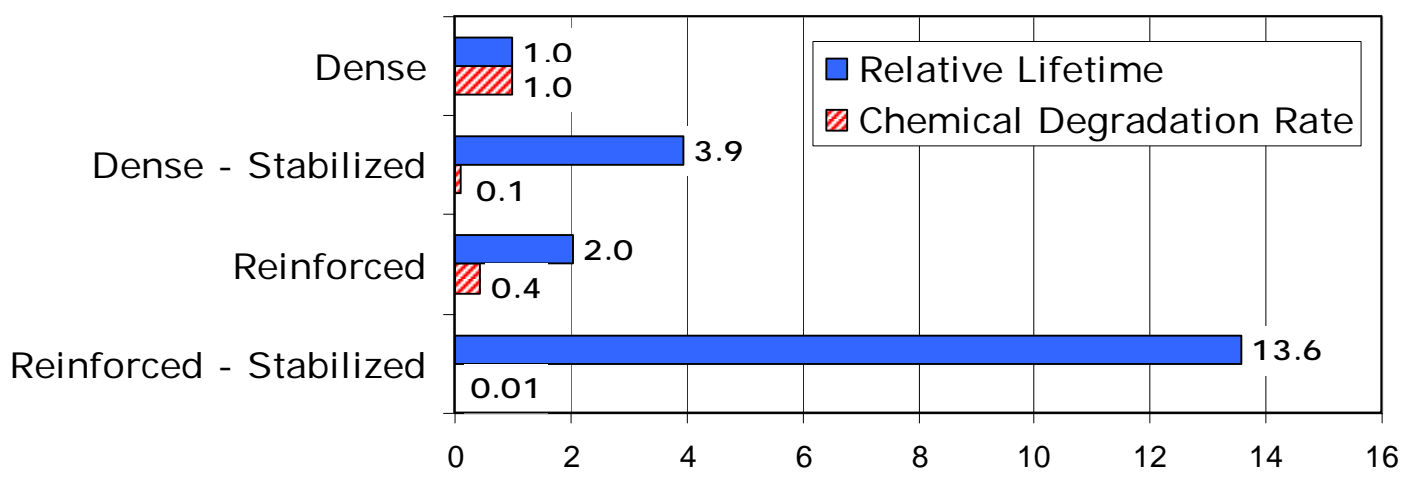

Figure 15. Impact of chemical and mechanical stabilization on membrane life and degradation under accelerated test conditions.

Mitigation of membrane degradation by both the appropriate choice of system components to reduce iron contamination of the stack, as well as the use of durable membrane material strategies, were implemented in a prototype hot water/electricity cogeneration system. In Figure 16, System 3 was much cleaner in terms of iron leaching, and on average contained less than half the iron concentration entering the stack, which when combined with a more durable membrane, resulted in two times the stack lifetime.

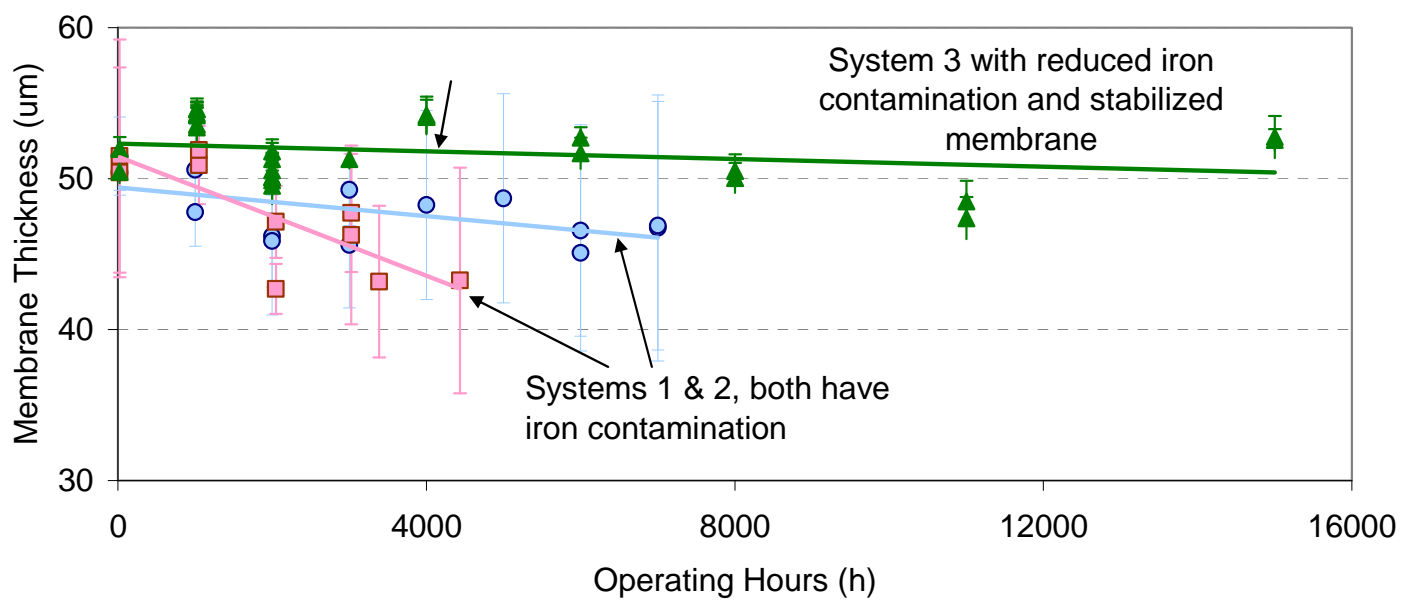

Figure 16. Membrane thickness in three stacks from three systems; membrane thickness measured in 9 regions for each sample.

\section{$\underline{\text { Electrode/Membrane Degradation Interactions and System Mitigation }}$}

While SU/SD degradation impacts on catalyst degradation, and idle or open circuit conditions impacts on membrane degradation have been discussed separately, in a system these are generally not mutually exclusive. For example, one method of reducing the number of starts is to keep air $/ \mathrm{H}_{2}$ on the cell and maintain open circuit voltage (OCV) rather than shut the cell down. In this case, the cell would see longer times at OCV and membrane durability would be sacrificed to reduce cathode performance degradation. Figure 17 below shows an example of the trade-off between time at idle/high potential (membrane degradation) and number of start-stop cycles from an air-air state. 


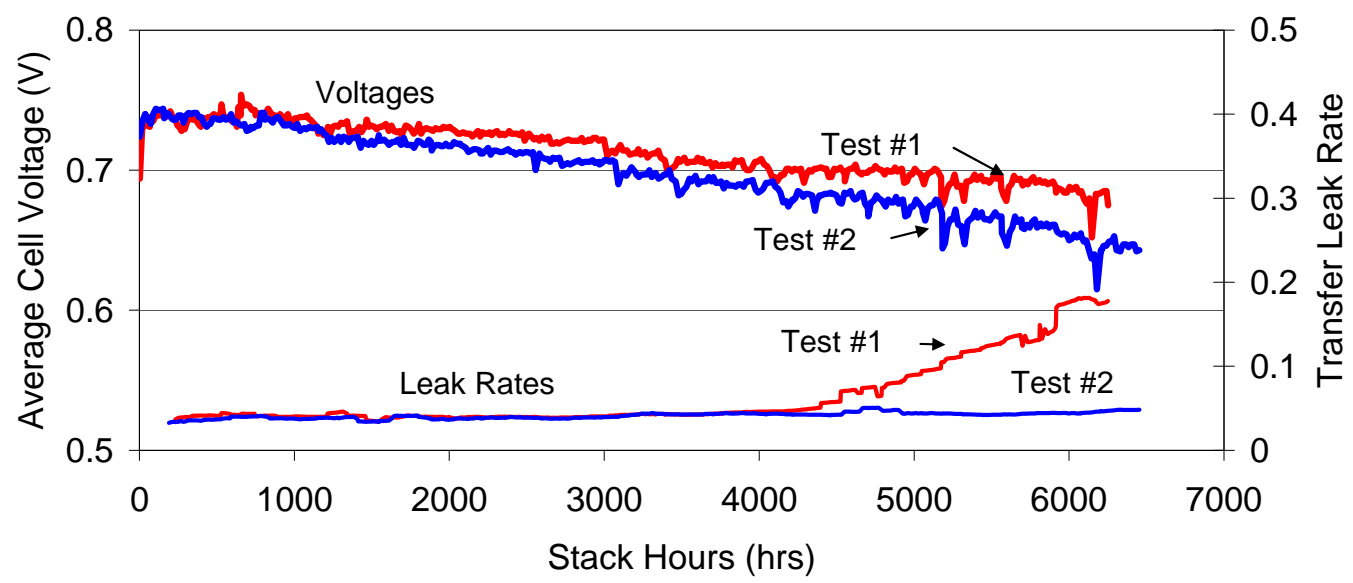

Figure 17. Effect of operating strategy on voltage degradation and membrane leak rate. Hardware: 27-cell air-cooled stack. Test \#1: Lower number of air-air starts and more time at idle and OCV. Test \#2: Higher number of air-air starts with less time at idle/OCV. Hardware: 27-cell air-cooled stack.

In Figure 17 the results are shown for two system lifetime tests; one was kept at idle for long periods of time and as a result offered a significant reduction in the number of air-air starts experienced by the stack (Test \#1), but as a result increased the chemical stress on the membrane. The other did not have a specialized operating strategy, had less time at idle/OCV conditions (Test \#2), and saw no leak initiation over the course of the test. The results indicate that for this system (Test \#1) an increase in time at idle or open circuit will reduce the number of air-air starts thereby reducing the voltage degradation rate; however the increased time at idle/OCV causes the membrane leak to initiate near 4000 hours. The upper limit of allowable leak rate and lifetime requirements will determine the extent to which the system would allow idle operation.

An added level of stack robustness and lifetime extension can take the form of how the system handles the advent of membrane holes, both in terms of durability and safety considerations. During normal shutdown, if a transfer leak does occur across the membrane, it is possible to have air transfer from the cathode to the anode causing increased local degradation from portions of the MEA being in an air-air state causing corrosion similar to that of a start-up event from air. On the other hand, cross-over of hydrogen from the anode to the cathode can provide benefits in terms of reduced cell voltages through consumption of the oxygen present on the cathode. This will reduce cell voltages and limit degradation.

In terms of safety, a further consideration is at what point the membrane degradation and hydrogen leak rate becomes unsafe, where this will be application and system dependent. Hydrogen/nitrogen mixtures on the cathode due to oxygen consumption, for example, are not a safety issue in the absence of oxygen. System design strategies to mitigate the effect of any gas cross-over and extend the product design lifetime can include limiting the cathode volume to ensure available oxygen consumption, using downstream dilution and gas mixing in the exhaust, and possibly the use of cathode exhaust catalytic converters. 


\section{Conclusion}

Key to designing an optimized system, with integrated stack and balance-of-plant, is a thorough understanding of the system requirements operating conditions and fuel cell interactions. Innovative system and MEA design approaches are also required to provide conditions and control strategies to extend stack durability. The best overall trade-offs will minimize cost while meeting the market requirements.

\section{Acknowledgments}

We thank the financial support from Natural Resources, Canada (CETC 823) and the U.S. DOE (DE-EE0000466 and DE-EE0000473)

\section{References}

1. T. Tabata, O. Yamazaki, Y.Oomori, H. Shintaku, ECS Trans., 11, 279 (2007).

2. P. He, T.T.H. Cheng, R. Bashyam, A.P. Young, S. Knights, ECS Trans., 33, 1273 (2007).

3. J.H. Choi, Y.S. Kim, R. Bashyam, P. Zelenay, ECS Trans., 1, 437 (2005).

4. T.T.H. Cheng, N. Jia, P.He, .J. Electrochem.Soc., 157, B714 (2010).

5. C. Reiser, D. Yang, R.Sawyer, US2002/0076582A1 (2002).

6. S. Ye, in PEM fuel cell electrocatalysts and catalyst layers: fundamentals and applications, J. Zhang ed., Springer, 835-860 (2008).

7. N. Yousfi-Steiner, Ph. Mocoteguy, D. Candusson and D. Hissel, J. Power Sources, 194, 130 (2009).

8. S. Knights, J.L. Taylor, D.S. Wainright, D.P. Wilkinson. US patent 6517962 (2003).

9. M. Miyake, M. Wakizoe, E. Honda, and T. Ohta, Electrochemical Society and The Electrochemical Society of Japan Meeting Abstracts, Honolulu, HI, Abstract 1880 (2004).

10. D.E. Curtin, R.D. Lousenberg, T.J. Henry, P.C. Tangeman, M.E. Tisack, J. Power Sources 131, 41 (2004).

11. W. Liu, K. Ruth, G. Rusch, J. New Mater. Electrochem. Syst. 4227 (2001).

12. E. Endoh, ECS Trans., 16, 1229 (2008).

13. F.D. Coms, H. Liu, J.E. Owejan, ECS Trans., 16, 1735 (2008).

14. P. Trogadas and V. Ramani J. Power Sources, 174, 159 (2007).

15. P. Trogadas, J. Parrondo, V. Ramani, Electrochem. Sol. Stat. Lett, 11, B113 (2008).

16. V. Ramani, H.R. Kunz, J.M. Fenton, J. Power Sources, 152, 182 (2005).

17. G.M. Haugen, F. Meng, N. Aieta, J.L. Horan, M.C. Kuo, M.H. Frey, S.J. Hamrock, A.M. Herring, ECS Trans., 3, 551 (2006).

18. D. Zhao, B. Yi, H.M Zhang, H.M. Yu, J. Mem. Sci., 346, 143 (2010). 